\title{
Laryngeal injuries and tracheal intubating conditions with or without muscular relaxation II
}

\author{
Mohammad El-Orbany, MD
}

Received: 19 November 2008/Revised: 15 December 2008/Accepted: 15 December 2008/Published online: 12 February 2009

(C) Canadian Anesthesiologists' Society 2009

\section{To the Editor,}

I read with interest the article about laryngeal injuries due to tracheal intubation with and without muscle relaxation. ${ }^{1}$ As the authors illustrated in Table III, patients in the placebo group required higher doses of propofol and remifentanil in order to satisfactorily achieve tracheal intubation. This is the trade-off when muscle relaxants are not included in the induction regimen. Excessive doses of induction and opioid drugs may be associated with undesirable side effects. ${ }^{2}$ It appears, from the authors' Table IV, that the incidence of unacceptable (poor) intubating conditions involved three patients in the placebo group (4.1\%) and none in the cisatracurium group. The incidence could have been much higher if the sample size was increased. I totally agree with Dr. Donati's editorial which expresses that our goal, with or without relaxation, should always be excellent intubating conditions. ${ }^{3}$ However, the authors, as well as other groups, have demonstrated that this goal is most likely achieved with minimal side effects when muscle relaxants are included in a balanced induction technique. ${ }^{1,4}$

Conflicts of interest None declared.

\section{References}

1. Bouvet L, Stoian A, Jacquot-Laperriere S, Allaouchiche B, Chassard D, Boselli E. Laryngeal injuries, and intubating conditions with or without muscular relaxation: an equivalence study. Can $\mathbf{J}$ Anesth 2008; 55: 674-84.

M. El-Orbany, MD ( $\square)$

Medical College of Wisconsin, Milwaukee, WI, USA

e-mail: elorbany@mcw.edu
2. Donati F. Tracheal intubation: unconsciousness, analgesia and muscle relaxation (Editorial). Can J Anesth 2003; 50: 99-103.

3. Donati F, Plaud B. Tracheal intubation: optimal conditions, vocal cord damage, and allergy (Editorial). Can J Anesth 2008; 55: 6639.

4. Lieutaud T, Billard V, Khalaf H, Debaene B. Muscle relaxation and increasing doses of propofol improve intubating conditions. Can J Anesth 2003; 50: 121-6.

\section{Reply}

We wish to thank Drs. Shetty, Sharma, Goneppanavar, Kaur (Correspondence I in this issue), and El-Orbany (Correspondence II) for their interest in our article.

Regarding our study design, propofol was administered $40 \mathrm{~s}$ after completing the injection of cisatracurium and remifentanil $2 \mu \mathrm{g} \mathrm{kg}^{-1}$. It is true that we did not assess whether patients experienced discomfort or an inability to breathe prior to their loss of consciousness. However, the mean onset time for cisatracurium is recognized to be $>3 \mathrm{~min},{ }^{1}$ and the onset time in our study was $>6 \mathrm{~min}$. Admittedly, monitoring the adductor pollicis muscle rather than the orbicularis oculi muscle probably led to our underestimation of cisatracurium's onset of action. Therefore, it can reasonably be assumed that patients were unlikely to have experienced symptoms of partial paralysis prior to their loss of consciousness.

As mentioned in our manuscript, unless the train-of-four ratio was $>0$ at $\mathrm{T}_{0}+270 \mathrm{~s}$, we did not administer an anesthetic agent during bag-mask ventilation prior to attempting laryngoscopy. In this case, continuous infusion of propofol $6 \mathrm{mg} \mathrm{kg}^{-1} \mathrm{hr}^{-1}$ was started and then discontinued once the fourth twitch response disappeared. In fact, if tracheal intubation was performed at $\mathrm{T}_{0}+270 \mathrm{~s}$, it occurred $210 \mathrm{~s}$ after the end of infusion of remifentanil and $120 \mathrm{~s}$ after the administration of propofol was completed, 
i.e., at the effect-site peak concentrations of both agents. ${ }^{2}$ Therefore, in our view, it was not necessary to administer additional hypnotic agent during the interval prior to laryngoscopy and tracheal intubation.

No supplemental muscle relaxant was administered in either study group, as the surgical procedure did not require muscle relaxation. Patients' reactions in response to surgical stimulation were not assessed in our study which focused on the incidence of symptomatic laryngeal injury (SLI) and acceptable intubating conditions with or without muscle relaxation.

Although female gender and gynecological surgery are well known factors for complaints of laryngeal symptoms after anesthesia, the incidence of sore throat was lower in our study compared to incidences reported in other trials. ${ }^{3}$ The use of smaller endotracheal tubes than those used in the study by Mencke et al. ${ }^{4}$ may have partially explained the lower incidence of laryngeal symptoms in our study. ${ }^{5}$ However, we agree with Dr. Shetty that intubating conditions in male patients could be different. Therefore, it would be of interest to conduct further studies assessing intubating conditions without muscle relaxation in this population of patients.

While assuming a $2 \%$ incidence of poor conditions and a $10 \%$ equivalence margin, our results demonstrated that the incidence of poor (i.e., not acceptable) intubating conditions was equivalent in both groups. When increasing the sample size, the difference observed would logically be statistically significant. In fact, if 800 patients were included in this study (assuming a $4.1 \%$ incidence of poor conditions in the placebo group and a $0 \%$ incidence in the cisatracurium group), Chi-square test would have given $\chi^{2}=16.65$, i.e., $P<0.001$, demonstrating a statistically significant difference between groups. For an equivalence designed study, an equivalence margin must be defined such that the difference between groups that is observed below the margin is not considered clinically relevant. ${ }^{6}$ For this equivalence study, the equivalence margin for the rates of acceptable (or poor) conditions was $10 \%$. If 800 patients were included, the Blackwelder's equivalence test would have given $z^{\prime}=-5.95$, i.e., $P<0.001$, and the $95 \%$ confidence interval between groups would have ranged from 2 to $6 \%$. This corroborates the statistical difference found between groups by using the Chi-square test, and it also allows us to conclude that there was equivalence, as the difference between the rates was $<10 \%$, i.e., within the equivalence margin.

We agree with Drs. Donati and Plaud that the assessment of "acceptable" intubating conditions can be somewhat imprecise, since the variability amongst conditions described as "good" can be quite important. Hence, we also described, analyzed, and discussed the incidences of excellent, good, and poor conditions.

However, since we found equivalent rates of SLI in both groups, our results remain of interest in spite of an increased incidence of excellent intubating conditions in curarized compared to non-curarized patients. This leads us to the issue of expecting to achieve excellent intubating conditions in order to minimize the incidence of SLI.

Conflicts of interest None declared.

\section{References}

1. Bluestein LS, Stinson LW Jr, Lennon RL, Quessy SN, Wilson RM. Evaluation of cisatracurium, a new neuromuscular blocking agent, for tracheal intubation. Can J Anesth 1996; 43: 925-31.

2. Minto CF, Schnider TW, Gregg KM, Henthorn TK, Shafer SL. Using the time of maximum effect site concentration to combine pharmacokinetics and pharmacodynamics. Anesthesiology 2003; 99: 324-33.

3. Christensen AM, Willemoes-Larsen H, Lundby L, Jakobsen KB. Postoperative throat complaints after tracheal intubation. $\mathrm{Br} \mathrm{J}$ Anaesth 1994; 73: 786-7.

4. Mencke T, Echternach M, Kleinschmidt S, et al. Laryngeal morbidity and quality of tracheal intubation. A randomized controlled trial. Anesthesiology 2003; 98: 1049-56.

5. Stout DM, Bishop MJ, Dwersteg JF, Cullen BF. Correlation of endotracheal tube size with sore throat and hoarseness following general anesthesia. Anesthesiology 1987; 67: 419-21.

6. Le Henanff A, Giraudeau B, Baron G, Ravaud P. Quality of reporting of noninferiority and equivalence randomized trials. JAMA. 2006;295:1147-51.

Lionel Bouvet, MD

Emmanuel Boselli, MD, PhD

Hôpital Édouard Herriot, Lyon, France 